\title{
Movimentos e mobilizações sociais no Brasil: de 2013 aos dias atuais
}

\author{
Social movements and mobilizations in Brazil: from 2013 to the \\ present day \\ Rudá Guedes Ricci1
}

DOI: 10.1590/0103-110420185308

RESUMO Este artigo trata da diferença conceitual entre as mobilizações do século XXI e os movimentos sociais do século passado, mais perenes e estruturalmente organizados que os atuais. Analisa o contexto e as características das mobilizações de junho de 2013, a reação governamental naquele ano e em 2014, o processo eleitoral e a reação de mobilizações de extrema-direita em 2015 e em 2016. Conclui que a provisoriedade e a relação instável com o campo institucional tornaram todas as mobilizações desse curto período inacabadas e sem consequências políticas visíveis em relação às práticas políticas vigentes.

PALAVRAS-CHAVE Participação social. Política. Brasil. Participação da comunidade. Extremismo.

\begin{abstract}
This article deals with the conceptual difference between the mobilizations of the 21st century and the social movements of the last century, which are more perennial and structurally organized than the present ones. It analyzes the context and characteristics of the mobilizations of June 2013, the governmental reaction in that year and in 2014, the electoral process and the reaction of far-right mobilizations in 2015 and 2016. It concludes that the provisional and unstable relationship with the institutional field have made all mobilizations of this short period unfinished and with no visible political consequences regarding current political practices.
\end{abstract}

KEYWORDS Social participation. Politics. Brazil. Community participation. Extremism. 


\section{Entre movimentos sociais e mobilizações}

O conceito de movimento social é, até o momento, muito delimitado. Originalmente, foi embebido em um estranhamento conservador, expresso pela pena de Lorenz Von Stein, em 1840, em relação à emergência do movimento operário francês e das reações populares ao processo de urbanização que não conseguia absorver a mão de obra vinda do meio rural.

Ao longo do século XX, o conceito passou a incorporar uma prática reativa, relativamente estável e perene, fundada no sentimento de marginalização e em uma multiplicidade de carências e demandas específicas. Alguns autores observaram nessa lógica política por direitos (não observados pelo poder constituído ou por novos direitos ainda não inscritos em lei) um desenho corporativo ou até mesmo um tipo novo de clientelismo ${ }^{\mathbf{1 , 2}}$. Teorias norte-americanas oscilaram entre as escolhas racionais que definiriam ciclos de protestos e dissensos que poderiam provocar crises políticas e institucionais, ameaçando provocar anomia. Já os europeus priorizaram a leitura de formação de identidades e cultura política comum. Sempre houve alguma dúvida se o fenômeno dos movimentos sociais abraçaria a lógica societal (de construção de unidade e diálogo entre desconhecidos e diferentes, em uma espécie de comunicação dialógica e democrática) ou meramente comunitária (definida por identidade entre iguais, com fortes laços afetivos que consolidam a unidade interna em oposição os diferentes ou expressões sociais externas). Contudo, sempre houve consenso a respeito da sua cristalização e da sua unidade interna a partir do sentimento de injustiça e exclusão social. De certa maneira, o conceito foi construído a partir dessa noção monossêmica, em que as ações coletivas eram galvanizadas a partir de pautas que possuíam um sentido articulador entre seus participantes, uma agenda de luta por direitos que cimentaria a unidade interna.

No Brasil, sociólogos vinculados ao Centro Brasileiro de Análise e Planejamento (Cebrap) sugeriram que os movimentos sociais que ressurgiram nos anos 1980 se constituíram a partir de um ideário comunitarista anti-institucionalista que mais significavam instrumentos de intermediação de interesses que sistemas de representação social. Assim, mobilizavam por direitos dos seus participantes, opunham-se à ordem institucional vigente, mas não alteraram estruturas de poder.

Contudo, já nos anos 1990, autores como Alberto Melucci ${ }^{3}$ percebiam algumas manifestações de movimentos sociais mais fragmentários, gerando forte imprevisibilidade. Naquela quadra da história social, já se insinuavam as formas e meios de comunicação que tinham nas redes sociais suas referências. Algo mais fluido e provisório.

Temos, a partir de então, um divisor de águas sobre os estudos e compreensão sobre movimentos sociais. Do conceito monossêmico para a polissemia; da estabilidade da organização e identidade interna dos movimentos sociais para a provisoriedade e imprevisibilidade de suas ações; do espírito coletivo para a manutenção da individualidade como elemento de respeito e preservação das liberdades civis. As mudanças das estruturas societais, aquelas que definem as relações em uma sociedade complexa, mais racionais e com baixos vínculos afetivos, passaram a determinar as alterações nas características das ações sociais.

O quadro 1 abaixo sintetiza as mudanças essenciais na lógica das ações sociais de massa: 
Quadro 1. Os comportamentos distintos de mobilizações sociais nos séculos XX e XXI

\begin{tabular}{ll}
\hline MOBILIZAC̣ÕES DO SÉCULO XX & MOBILIZAC̣ÕES DO SÉCULO XXI \\
\hline Preservação da individualidade & Predominância do coletivo \\
Adesão por convicção e emoção & Militância segue orientação da organização \\
Vincula-se pontualmente a uma ação & Vincula-se a um programa ou meta \\
\hline
\end{tabular}

Como o quadro 1 sugere, vivemos uma alteração importante na lógica comunicativa e organizacional das mobilizações sociais. Se na segunda metade do século passado havia certa previsibilidade e organicidade nas mobilizações que, não tendo sua pauta atendida, perpetuavam-se em movimentos sociais compostos por estruturas próprias (de formação política de sua base social, de liderança e comunicação, entre outros), no atual século, a lógica é mais provisória e dinâmica. A estrutura de organização é lacunar, ou seja, não tem todas suas estruturas internas preenchidas (cúpula, corpo administrativo ou de organização interna e militância de base). Não são tão horizontalizados como seu marketing sugere, mas utilizam expedientes de consulta permanente aos seus componentes, quase sempre por meio de recursos disponíveis na internet, como WhatsApp ou instrumentos de comunicação rápida e de baixo custo, mais afeita à lógica comunitária fechada.

A provisoriedade foi denominada por alguns autores de 'enxameamento' (swarming, na literatura de língua inglesa), analisado por Fábio Malini ${ }^{4}$, pesquisador de redes sociais da Universidade Federal do Espírito Santo. As organizações, profundamente fragmentadas e dispersas, promoveram a polifonia que desorienta qualquer estrutura organizacional mais perene e verticalizada. O historiador Peter Lamborn Wilson, conhecido nas redes sociais pelo pseudônimo Hakim Bey, chegou a sugerir a configuração de Zonas Autônomas Temporárias (TAZ) do inglês Temporary Autonomous Zone, cujas características centrais seriam o não estabelecimento de lideranças fixas, lideranças temporárias locais, lideranças descentralizadas e ausência de padronização do movimento.

A figura 1 apresentada em seguida sugere uma estrutura organizacional radicular e randômica. Um participante desta rede pode se relacionar diretamente com vários outros participantes ou comunidades que nem sempre estão conectadas diretamente entre si. O participante inicial torna-se um pivô das múltiplas relações e conexões sem, contudo, sentir-se obrigado a estabelecer tais nexos. Nem mesmo sua participação em todas as relações originalmente estabelecidas pode ser mantida por muito tempo. 
Figura 1. A estrutura de relacionamento nas redes sociais

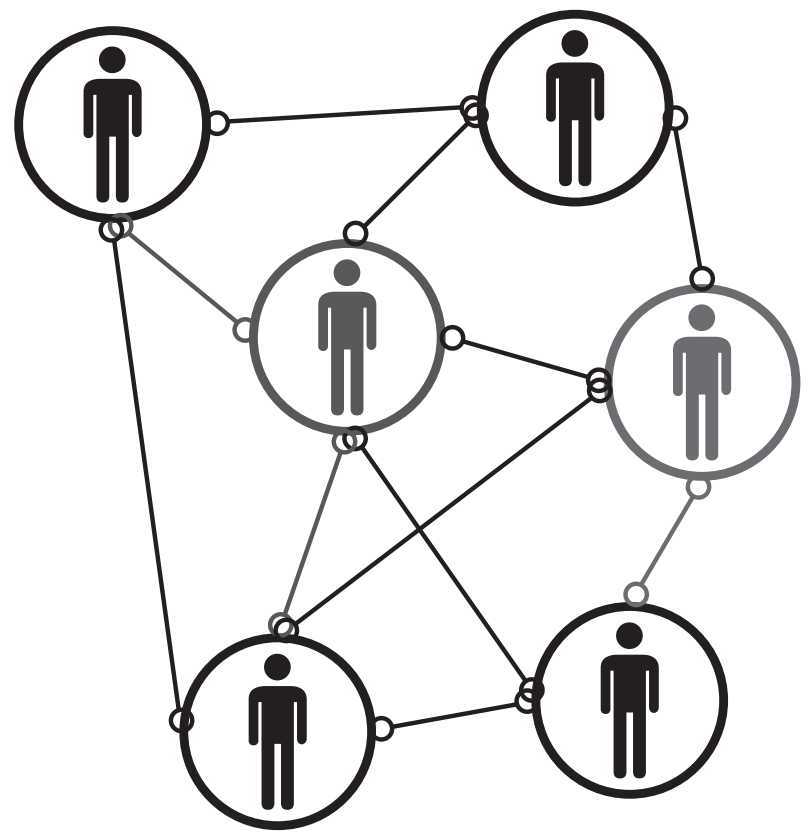

Fonte: Reis 5

Os vínculos estabelecidos são fortuitos e provisórios, estabelecendo laços comunitários que muitos autores sugerem ser 'espelhados', ou seja, definidos por forte identidade de valores, crenças ou ideários, criando uma imagem refletida que exclui a divergência.

As redes sociais lacunares (estruturas que possuem buracos nos seus vínculos internos, tal como sugerem os autores de língua inglesa que empregam o conceito de structural holes, desenvolvido por Ronald Stuart Burt ${ }^{7}$ ) promovem núcleos de 'subculturas' autorreferentes, a provisoriedade e a ação social por 'enxameamento', percebidas nitidamente em junho de 2013.

Assim, temos certa descontinuidade e fragmentação de ações que dão sentido aos cartazes exibidos ao longo das manifestações juninas daquele ano que afirmavam que haviam saído do Facebook $^{\circledR}$. A observação era límpida ao desnudar as inúmeras comunidades espelhadas, fechadas em seus ideários e valores, que se espalharam sobre as ruas de grandes centros urbanos, criando uma 'carnavalização política', forjada em suas alas e paisagem caótica.

Essa dinâmica polissêmica se chocou com estruturas analíticas racionais e compactadas, definidas por conceitos totalizantes que pouco dialogavam com essa novidade social.

Para efeito de síntese, é possível sustentar que as mobilizações de 2013 apresentaram, ao menos, cinco características essenciais. $\mathrm{O}$ leitor perceberá que muitas delas parecem se cruzar em uma espécie de desmembramento ou ênfase. São elas:

\section{Provisoriedade e descontinuidade}

Esta característica tem relação direta com a lógica interna dos movimentos, caracterizada pela entropia, uma desordem organizacional causada pelo estabelecimento da descentralização dos núcleos de comunicação interna. Não há um comando organizacional ou de comando das mobilizações. Esta característica debela representações 
fixas fundadas em lideranças perenes, estáveis ou únicas. As relações com o campo institucional são profundamente prejudicadas por esta característica e há exemplos disponíveis em profusão. Em 2013, nos meses que se seguiram às mobilizações de junho, alguns governos estaduais (como o mineiro) procuraram estabelecer diálogos com comitês temáticos que permaneceram atuantes, como foi o caso dos comitês de mobilidade urbana ou de educação. As negociações, contudo, revelaram-se infrutíferas na medida em que os participantes-ativistas se recusavam a se apresentar como representantes, gerando um rodízio permanente de pautas e ativistas presentes nas mesas de negociação. Em 2018, durante a greve dos caminhoneiros, situação similar ocorreu ao se estabelecer um acordo entre dirigentes sindicais da categoria e governo federal, acordo assinado e fartamente divulgado pelos meios de comunicação que se revelou, no dia seguinte, um engodo, dado que os núcleos de caminhoneiros autônomos espalhados pelo País permaneceram parados, dando continuidade ao movimento. As lideranças oficiais se revelaram protocolares e formais. Dias depois, um novo acordo colocou fim à mobilização, embora não tenha contemplado a maioria das demandas da categoria. O governo federal afirmou que negociou em duas frentes, com os dirigentes constituídos e a partir de conversas realizadas em 'grupos de WhatsApp'. A paralisação foi se desfazendo lentamente. Mesmo depois de algumas lideranças de base decidirem retomar a mobilização em virtude do não cumprimento integral do acordo estabelecido, foi impossível retomar a organização da categoria. A provisoriedade e a descentralização são marcas dessa nova forma de fazer política neste século que se inicia.

\section{Comunitarismo, auto-organização e espelhamento}

As comunidades fechadas reforçam o que um dos fundadores da sociologia francesa, Émile Durkheim, desenvolveu a partir do conceito de solidariedade mecânica. A solidariedade mecânica, ao contrário da orgânica, é aquela definida pela identidade afetiva entre seus membros. Ocorre em agrupamentos menores, em que todos se conhecem e sua história coletiva define valores que cimentam a unidade grupal. Por esse motivo, não são afeitos à tolerância em relação às críticas ou aos valores e opiniões que divergem dessa identidade comunitária. Em 2013, essa solidariedade se revestiu pela noção do 'comum', elaboração cara a Antonio Negri. Em seu livro 'Multidão: guerra e democracia na era do Império', Hardt e Negri ${ }^{\mathbf{8}}$ sustentam a possibilidade de constituição da multidão como agente político. Propõe Negri9(2):

Quando falamos de multidão falamos de um conjunto, mais do que uma soma, de singularidade cooperantes. A multidão pode ser definida como o conjunto de singularidades cooperantes que se apresentam como uma rede, uma network, um conjunto que define as singularidades em suas relações umas com as outras. Este fato levanta problemas e é preciso esclarecer que são essas singularidades que se movem desta maneira e que se colocam nesta relação. A primeira característica que aparece vem definida pelo fato de que não estamos aqui diante de individualidade e sim diante de singularidades. Individualidade significa algo que está inserido em uma realidade substancial, algo que tem uma alma, uma consistência, por separação em relação à totalidade, em relação ao conjunto. É algo que tem uma potência centrípeta. [Na] multidão [...], vivemos com os outros, a multidão é o reconhecimento do outro. A singularidade é o homem que vive na relação com o outro, que se define na relação com o outro. Sem o outro ele não existe em si mesmo.

A multidão, ao contrário da tradição conservadora, é apresentada como provida de certa racionalidade cooperativa, conformando uma rede. Algo não necessariamente observado em grandes mobilizações cuja característica é a soma de comunidades 
autorreferentes, apartadas entre si. Contudo, para Negri ${ }^{9}$, as singularidades - que o autor distingue de individualidades - se reconhecem, e a multidão ganha um estatuto político, próximo da noção rousseauniana.

Muitos coletivos autonomistas emergiram em 2013 empunhando essa politização das ações coletivas de grandes dimensões. Foram além e sugeriam a ocupação de espaços públicos para construção, in loco, da utopia da comunhão em rede. Um projeto novo de relações sociais, portanto.

Vale destacara que a definição dos autonomistas não é das mais fáceis, como sustenta a antropóloga Alana Moraes ${ }^{10}$ :

É difícil definir o que são os movimentos autonomistas hoje, é uma constelação bastante diversa de pequenos grupos que vêm misturando debates sobre formas de organização mais horizontais com outros debates sobre concepção de luta revolucionária, sobre o papel da classe trabalhadora, formas de conscientização, trabalho de base, tática etc. Podem misturar, por exemplo, como influências de forma de organização o zapatismo, mas, do ponto de vista da relação com a classe trabaIhadora, apostar em estratégias de 'proletarização' de seus militantes, como os trotskistas faziam aqui na década de 1970 nas fábricas.

O autonomismo foi uma referência recorrente de lideranças de junho de 2013 que, muitas vezes, cruzava-se com princípios e teses anarquistas. A noção de coletivo (pequeno agrupamento de natureza comunitária e libertária) e de horizontalidade (de caráter assembleístico, sem lideranças fixas) passaram a orientar as formas organizativas naquele período. Estruturas totalizantes e verticais, com nítida intenção integrador, foram refutadas. Até mesmo as formas de decisão coletiva nas assembleias que ocorriam nas ruas de grandes centros urbanos no período foram inovadoras e seguiram tais orientações. Esse é o caso da Assembleia Popular Horizontal, realizada durante as manifestações que ocorreram em junho na capital mineira. Nas reuniões públicas que ocorriam embaixo de um viaduto no centro de Belo Horizonte, havia sempre um coordenador (ou motivador) da assembleia à frente da multidão e outro, empunhando um microfone, que se misturava ao aglomerado de 1,5 mil pessoas. A intenção deste segundo era dar voz aos mais tímidos ou aos que não eram iniciados na lógica dos movimentos organizados que, não raro, invocavam questões de ordem e outros códigos empregados por ativistas mais experientes. A 'mesa' que se postava atrás do 'coordenador de palco' da assembleia era sorteada entre os presentes, em uma clara oposição à composição a partir das principais forças organizadoras do evento. Evitavam-se desaprovações ostensivas a propostas rejeitadas pela assembleia, buscando respeitar as minorias. Enfim, havia uma nítida preocupação em não impor uma ordem preestabelecida que pudesse coibir manifestações individuais ou mesmo de minorias ali presentes.

\section{Individualismo}

No final dos anos 1960, Licklider e Taylor"1 já haviam sugerido que as novas tecnologias criavam uma visão da sociedade totalmente focada na realização dos indivíduos. As opções individuais se ampliam a partir da possibilidade de escolha quanto à qual comunidade deseja pertencer. Logo em seguida, Richard Sennett ${ }^{\mathbf{1 2}}$ publica um instigante ensaio sobre a emergência de um profundo ressentimento social a respeito de qualquer autoridade pública, o que propicia um fechamento espontâneo dos indivíduos em seus círculos mais íntimos e comunidades fechadas, preservando seus valores em uma sociedade que se apresenta promíscua e recheada de privilégios para quem ascende socialmente.

A marca do hiperindividualismo que passa a determinar escolhas fragmenta a sociedade em necessidades e interesses múltiplos, em detrimento de valores universais e até 
mesmo da noção de direitos. É a demanda instantânea que passa a ser valorizada e a motivar ações grupais ou associativismos em pequena escala. Tal situação engendra, em muitos casos, o advento do 'pensamento mágico', a exigência pessoal que sua vontade deve ser respeitada ou cumprida instantaneamente como determinação legítima. Todas as organizações ou os instrumentos de representação social de amplo espectro passam a ser objeto de profunda desconfiança social.

Este é o momento da organização social em forma de mosaico, estilhaçada em inúmeros interesses semiautônomos que se apresentam com linguagem e valores específicos em que os aspectos antropológicos (culturais e fundado em histórias grupais) valorizam as pequenas narrativas comunitárias e comuns.

\section{Horizontalidade}

Jean-Pierre Dupuy ${ }^{13}$ percebeu na lógica cibernética processos 'sem sujeitos', marcada por uma 'ordem espontânea'. Na prática, sustentava que se constituía uma sociedade sem hierarquias ou regras gerais com forte ausência de controle de conjunto ou estabelecimento de uma ordem geral. A auto-organização, na percepção desse autor, parecia mais programada pelo mercado ou por forças externas imperceptíveis ${ }^{\mathbf{1 4}}$.

A compreensão da lógica cibernética e das redes sociais, dos anos 1960 aos dias atuais, sempre variou entre a percepção de um total controle externo sobre as ações de seus participantes e a sua auto-organização. Patrice Flichy, em um ensaio de 2001, destacou os princípios estabelecidos por universidades norte-americanas que colaboraram para o esforço de construção da internet: comunidade de iguais em que o estatuto e os argumentos de autoridade são minimizados; colaboração e trabalho em equipe; e um mundo à parte, funcionando de acordo com regras particulares ${ }^{\mathbf{1 4}}$.

É possível depreender que parte do discurso da horizontalidade na tomada de decisões coletivas que se expressa nas mobilizações de massa no início do século XXI dialoguem com a lógica comunitária que as redes sociais possibilitam. Horizontalidade que preserva as individualidades, as escolhas pessoais e até mesmo a mobilidade descompromissada dos participantes das diversas comunidades virtuais. Algo que remete à autorregulação e à autopreservação.

\section{Anti-institucionalismo e cultura antissistêmica}

Finalmente, a cultura antissistêmica, fundada na desconfiança em relação às grandes estruturas organizativas e regras universais de comportamento que supostamente inibiriam a liberdade individual.

O anti-institucionalismo, vale recordar, já se expressava nos anos 1980 por meio dos Novos Movimentos Sociais (NMS) que emergem na Europa Latina e no Brasil, campo de estudos da sociologia europeia e brasileira nos anos 1980 e parte dos 1990. Naquela quadra, já se disseminava a valorização entre iguais contra as estruturas de poder vigentes, compreendidas como estruturas de preservação de poder das elites. Aos 'de baixo', expressão que será recuperada nas mobilizações de massa da Europa deste início de século XXI (em especial, na Espanha após as grandes mobilizações de 2011), caberia a auto-organização e a construção da identidade pela diferença, procurando impor suas demandas mediante uma permanente organização da base excluída social, política e economicamente, no que se denominou de 'mobilismo'. Aqui já se valorizavam as formas de democracia direta na tomada de decisões entre participantes de movimentos sociais, a desconfiança em relação às lideranças sociais com pouca presença nas organizações de base e a rejeição às práticas e terminologias muito técnicas ou rebuscadas.

$\mathrm{O}$ anti-institucionalismo gerou, nos anos 1980, grande rejeição às negociações e participações em fóruns institucionalizados, 
tema explorado em muitos estudos especializados'. Contudo, na medida em que houve convergência entre movimentos sociais, estruturas sindicais e a construção de novos partidos políticos, o campo institucional foi gradualmente sendo ocupado por eleições de representações delegadas - aquelas em que o representante possui um viés nitidamente corporativo, representando exclusivamente a base social que o elegeu -, algo que não se repetiu neste início de século XXI. Ao contrário, a rejeição ao campo institucional foi ainda mais forte, e o valor político da horizontalidade e desconfiança em relação às lideranças impediu qualquer negociação com a esfera institucional pública que fosse estável ou duradoura. As mobilizações eram valores em si, 'utopias realizadas no presente', projetos imediatos de tomada dos espaços públicos fundados em profundo desprezo às instâncias formais e institucionalizadas das práticas sociais e políticas.

Um ano após as manifestações de 2013, os jornalistas Estelita Carazai e João Pedro Pitombo ${ }^{15}$ analisaram a efetividade dos acordos firmados entre manifestantes e governos municipais e estaduais. Apenas as propostas de curto prazo haviam sido cumpridas, como a redução das tarifas de ônibus e descontos para estudantes. O levantamento que os dois jornalistas realizaram revelou, entre outras situações, que:

1) Em Pernambuco, a Câmara do Recife não realizou concurso público para a redução dos comissionados.

2) Ainda nesse estado, a Assembleia Legislativa enterrou as discussões sobre voto aberto e sobre a implementação da lei de acesso à informação.

3) No Paraná, a divulgação mensal dos índices de qualidade dos ônibus e da tarifa mais barata fora do horário de pico ainda seguiam na gaveta.
4) No Rio Grande do Sul, nada de 'abertura das planilhas' do transporte metropolitano e análise para detectar 'gorduras' nos custos do sistema.

5) Em Minas Gerais, nenhum estudo para tratar de soluções para a integração tarifária da região metropolitana de Belo Horizonte.

6) Na Bahia, a Prefeitura de Salvador não detalhou a planilha de gastos de cada uma das empresas de ônibus.

7) Também nesse estado, a Assembleia não aprovou a PEC, vetando a reeleição do presidente da Casa no mesmo exercício.

8) No Amazonas, nada de implantação de zona azul e da comissão para investigar as empresas de ônibus.

9) No Ceará, gaveta para a promessa de plebiscito para aprovar obras polêmicas do governo.

10) Ainda nesse estado, a Câmara Municipal não criou o Conselho de Ética da Casa.

Esse cenário desolador é similar a quase totalidade de manifestações de mesmo tipo que se espraiaram no mundo desde o início do século XXI. Como já expressei no livro que escrevi sobre as manifestações de massas no início deste século:

Com exceção da experiência argentina, todas que se seguiram tiveram nas redes sociais um forte mecanismo de comunicação e convocação de ações sociais, além de se adequar aos valores políticos de horizontalidade e ausência de liderança que todos os protestos de massa sustentaram. [...]

Há, contudo, uma diferença nítida da pauta e evolução das ações políticas das experiências europeias (Espanha e Islândia) e dos EUA em relação às demais. Nelas, o conteúdo 
anticapitalista e confronto ao vínculo das estruturas políticas com os conglomerados empresariais deram consistência ideológica desde o início. Na América Latina e Ásia, as mobilizações de massa foram, muitas vezes, personalizadas na figura de uma ou outra autoridade pública ou tiveram uma pauta extensa e difusa, muitas vezes negando o campo institucional como campo de disputa.

Todas as experiências, contudo, não foram estáveis e não apontaram alternativas na estrutura de poder, muito menos no aparato institucional de representação e práticas políticas. Em todos os casos, o sistema político e as elites governantes se mantiveram no poder ou retornaram após um surto catártico das manifestações de rua. [...]

Em outras palavras, a cultura antiinstitucionalista se reproduziu e agregou muitos adeptos. Mas o que agregou, pela declarada intenção de não liderar ninguém e permitir que todas as vozes tivessem o mesmo peso político, estagnou seu desenvolvimento político-organizativo. Como se o lugar deste discurso fosse, até o momento, a própria catarse popular, a explosão emocional sem finalidade objetiva, sem conclusão política.

A insatisfação continua latente. Mas as experiências organizativas não passaram de experimentações iniciais ${ }^{\text {16(11-12). }}$

\section{$O$ interregno de 2014 e a avalanche reacionária de 2015 e 2016}

Desde 2013, o Brasil mergulhou em uma disputa de interpretações sobre o legado e intencionalidade das mobilizações daquele ano - uma disputa ideológica e partidária. Não se trata de uma novidade no Brasil: nos anos 1980, a interpretação sociológica e histórica sobre a ascensão do varguismo foi palco de um encarniçado embate teórico entre a versão de historiadores que sugeriam ter sido uma revolução (a tese foi explicitada no livro de Boris Fausto ${ }^{17}$, ex-militante do Partido Comunista Brasileiro) e as teses da nova historiografia brasileira que sugeria uma disputa entre frações da classe dominante e não propriamente uma revolução ${ }^{\mathbf{1 8}}$.

Da mesma maneira, a interpretação sobre 2013 se tornou um campo de disputa política. Do campo lulista, advém a tese que se tratava de uma manifestação estimulada por interesses de extrema-direita ou que tais interesses se insinuaram sobre as mobilizações que inicialmente pareciam espontâneas. Esse ano teria aberto uma temporada de ataques às forças de esquerda do País, desencadeando uma escalada de discursos e mobilizações de caráter fascista.

$\mathrm{Na}$ outra ponta das análises, temos autores que sustentam que não haveria correspondência entre 2013 e as mobilizações nitidamente de direita que se insurgiram a partir de 2015.

Com efeito, embora blocos de manifestantes de direita estivessem presentes nas mobilizações de São Paulo e de Brasília, na maioria dos casos, as manifestações de 2013 tiveram nítido perfil de esquerda. Em algumas localidades, como em Belo Horizonte, foram adotadas, inclusive, palavras de ordem que expressavam esta postura (como a palavra de ordem surgida na primeira assembleia aberta das manifestações, preparatória de uma das concentrações: 'somos todos de esquerda'). No Rio de Janeiro e em Porto Alegre, os coletivos anarquistas (as duas capitais acolhem as duas maiores federações anarquistas do País) e autonomistas protagonizaram as ações de rua. A própria tática Black Bloc ${ }^{19}$, de origem anarquista, foi fartamente empregada e explorada pela grande imprensa em editoriais que atacavam sem trégua as manifestações daquele período.

Uma leitura mais atenta do desenrolar da reação governamental a partir de julho de 2013 indica uma rápida desmontagem das ações dos manifestantes de junho.

A primeira reação do governo federal foi, já no final das manifestações, em 24 de junho, durante uma reunião realizada no Palácio do 
Planalto, envolvendo 27 governadores e 26 prefeitos de capitais convidados. Naquela oportunidade, o governo federal apresentou a proposta de pacto nacional lastreado em cinco eixos temáticos: responsabilidade fiscal, reforma política, saúde, transporte e educação. A polêmica maior se concentrou no eixo reforma política, tendo como carro-chefe a convocação de um plebiscito para decidir sobre a convocação de um processo constituinte específico destinado a fazer a reforma política.

No mesmo período, a Presidente Dilma Rousseff convocou uma reunião com lideranças sociais nacionais de todo o País, também realizada no Palácio do Planalto. Nessa reunião, diversas lideranças convocadas manifestaram estranheza por não terem sido requisitadas antes e por não estarem envolvidos nas manifestações de junho. As propostas governamentais não vingaram.

Em outubro de 2013, a estratégia governamental se alterou. O então ministro da Justiça, José Eduardo Cardozo, convocou os secretários de Segurança Pública de São Paulo e do Rio de Janeiro para discutir ações conjuntas a fim de evitar o que qualificou como atos de vandalismo em manifestações públicas. O ministro sustentou:

Discutiremos medidas de segurança pública que devem ser tomadas para evitar esses atos. $\mathrm{O}$ que não significa que devamos reprimir a liberdade de expressão ${ }^{20}$.

O temor de que as manifestações se alastrassem pelo País e acabassem por contaminar a realização da Copa do Mundo de Futebol que se realizaria em meados de 2014, assim como o processo eleitoral que reelegeria Dilma Rousseff, fez o governo federal apertar o cerco aos manifestantes de junho. Em fevereiro de 2014, uma nova reunião convocada pelo ministro da Justiça envolveria todos os secretários de segurança das 12 cidades-sede da Copa de Futebol ${ }^{21}$.

Antes, contudo, duas ações preparam o terreno para a ofensiva. A primeira, o treinamento de forças de repressão estaduais e federais nos Estados Unidos ${ }^{22}$. Foram treinados 22 agentes e policiais militares para desenvolverem atividades 'antiterroristas'. O curso foi ministrado pela Blackwater Personal Security Detail, hoje Academi, uma organização 'terceirizada' de mercenários, que é conhecida, justamente, por ter auxiliado os Estados Unidos, em vários países do mundo, em atividades de terrorismo de Estado, com denúncias de ataques a civis, como no caso de um tiroteio descontrolado contra uma multidão desarmada de civis iraquianos, que deixou um saldo de 17 mortos e dezenas de feridos, na Praça Nisour, em Bagdá.

O segundo movimento foi o da publicação do 'Manual de garantia da lei e da ordem' que, em determinado momento, sugere acompanhamento e repressão a movimentos sociais, embora em seu início destaque ações contra atos terroristas ${ }^{23}$.

A guinada repressiva do governo ganha robustez após a morte de um cinegrafista da Band News, em 6 de fevereiro de 2014. O cinegrafista Santiago Andrade foi atingido por um rojão que teria sido disparado por manifestantes, durante protestos contra a Copa de Futebol realizada na Central do Brasil, no Rio de Janeiro. Dois manifestantes foram acusados e presos. A reação da grande imprensa foi imediata, procurando vincular o incidente com as práticas Black Bloc que se projetaram a partir do final das manifestações de junho de 2013.

O ano 2014 teve início com os ânimos exacerbados. Logo no primeiro mês do ano, os rolezinhos, encontros fortuitos de pré-adolescentes e adolescentes residentes em periferias de grandes centros urbanos, passaram a ser percebidos por parte da grande imprensa e setores mais abastados da sociedade como perigos iminentes.

Os rolezinhos foram mais um fenômeno passageiro no período e, de certa maneira, revelaram novos personagens sociais oriundos das mudanças recentes pelas quais passou o Brasil. Residentes das periferias, 
adolescentes de baixa renda e, em sua maioria, negros acessavam as redes sociais, em especial o Facebook ${ }^{\circledast}$ (que, na época, acolhia 58 milhões de brasileiros ativos, sendo os adolescentes e jovens o principal público), para estabelecer conexões entre si, tendo como único objetivo a diversão. Desde o seu início, houve relação com o funk. Em São Paulo, funkeiros passaram a utilizar essas conexões a partir de suas páginas no Facebook $^{\circledR}$, procurando incentivar reação a um projeto de lei que proibia bailes nas ruas da capital paulista. Rapidamente evoluíram para um tipo de organização social fechada, comunitária, em que um jovem agregava seguidores nas suas páginas e, em troca, divulgava fotos, vídeos e elogios a eles. Em seguida, a multidão que foi se formando ao redor dessas páginas (houve registros de mais de 100 mil seguidores em diversas páginas) passou a se concentrar em encontros nos shoppings centers instalados nas periferias dos grandes centros urbanos. Nesses encontros presenciais, seguidores dos 'líderes' (como eram nomeados os proprietários das páginas mais seguidas no Facebook $^{\circledR}$ ) os presenteavam com CDs, camisetas e bonés, o que estimulou uma disputa entre 'líderes' para capturar mais seguidores. Os encontros presenciais se tornaram grandes eventos que arrastaram multidões juvenis aos shoppings, multidões que entoavam as letras agressivas e erotizadas do funk. Expunha-se o que mais tarde seria conhecido como o 'funk ostentação', baseado no aumento de consumo de marcas de grife e superexposição de seus expoentes.

Muitas direções de shoppings centers reagiram de maneira negativa, procurando respaldo judicial para fazer a triagem de clientes. Vários centros comerciais empregaram força policial ou fecharam suas portas para impedir o afluxo das multidões adolescentes.

A reação exagerada repercutiu e motivou a convocação de rolezinhos país afora, no nordeste, sudeste e sul do Brasil24.

Muitas decisões judiciais impuseram multas vultosas aos líderes de rolezinhos e muitos deles tiveram buscas e apreensões em suas casas, onde policiais recolhiam computadores e celulares que configurassem a articulação dos atos considerados abusivos ou criminosos. Em São Paulo, a Polícia Militar chegou a empregar bombas de gás lacrimogêneo e efeito moral, além de balas de borracha, contra um grupo de aproximadamente mil pessoas que se reuniram para um rolezinho no Shopping Itaquera, na zona leste da cidade.

Tal expediente repressivo e de inibição de atos infanto-juvenis se espraiou pelo País naquele início de 2014 em uma escalada que atingiu seu ápice durante a realização da Copa do Mundo de Futebol.

A ação repressiva estatal era estimulada por manchetes agressivas contra o descontrole e contra a violência desencadeada pelas práticas Black Bloc, que se somaram à reação de segmentos da classe média do centro-sul do País contra o abuso e contra a invasão de camadas pobres da sociedade em ambientes até então de uso exclusivo das classes mais abastadas brasileiras, como shoppings centers, aeroportos, restaurantes e concessionárias de venda de veículos domésticos. As reações disseminadas nas redes sociais foram intensas e rapidamente evoluíram para ataques pessoais, muitas vezes racistas ${ }^{25}$.

Não havia, contudo, nenhuma reação organizada ou agrupamentos de extrema-direita liderando ou motivando tais reações. O que tínhamos, até então, era um caldo de cultura forjado na intolerância de classe que se expunha publicamente.

Durante a Copa do Mundo de Futebol, a ação repressiva foi intensificada. Em muitas capitais, as mobilizações contra o evento esportivo - coordenadas pelos Comitês da Copa organizados nas 12 cidades-sede dos jogos - foram muito menores que as realizadas no ano anterior, durante a Copa das Confederações. Mesmo assim, a reação repressiva foi muito mais agressiva.

Em diversas localidades, as Polícias Militares empregaram o 'Caldeirão de Hamburgo' como instrumento de intimidação 
e cerco aos manifestantes. Essa tática surgiu em 1986, quando policiais da cidade alemã cercaram por 13 horas 800 pessoas que protestavam, deixando-as sem comida e água. Tempos depois, esse expediente foi proibido na Alemanha. Durante a Copa do Mundo, contudo, foi recorrentemente empregado, cercando manifestantes ao redor de praças ou mesmo quarteirões, diminuindo espaços de locomoção. Em Belo Horizonte ${ }^{26}$, após o cerco, a repressão policial liberava lentamente os manifestantes, um a um, e não raro os perseguia quarteirões adiante ${ }^{27}$.

A soma da repressão policial e a reação de camadas médias da sociedade e da grande imprensa inibiram os manifestantes de 2013 e 2014. Não houve, ao contrário de certa interpretação sobre o desenrolar dos acontecimentos no período, nenhuma reação organizada da extrema-direita.

Esfacelada e perseguida, a liderança jovem que iniciava um esboço de organização e ação coletiva recuou. O segundo semestre de 2014 foi totalmente dedicado às eleições. Eleições que se revelariam as mais agressivas do período que sucedeu o regime militar.

\section{As eleições de 2014 e a emergência das organizações de extrema- direita}

As manifestações de junho de 2013 provocaram queda da intenção de voto de Dilma Rousseff, que despencou entre março e junho, só se recuperando levemente no segundo semestre daquele ano, como demonstra figura 2 da sequência de pesquisas produzidas pelo Datafolha:

Figura 2. Intenção de voto para presidente em 2014

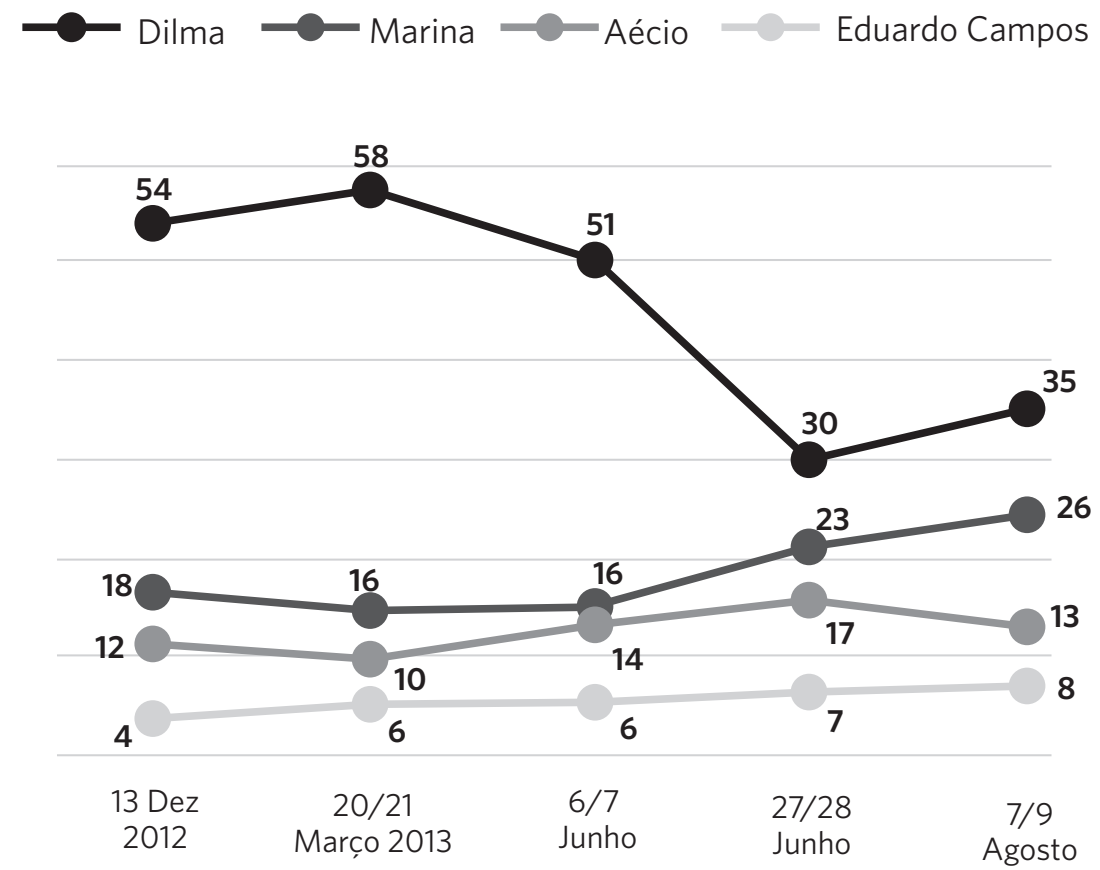


Durante o primeiro turno, a candidatura de Marina Silva chegou a emparelhar com a candidatura de Dilma Rousseff em setembro para, então, começar uma constante queda, até trocar de posição com Aécio Neves, já no mês de outubro, conforme figura 3.

Figura 3. Intenção de voto para presidente
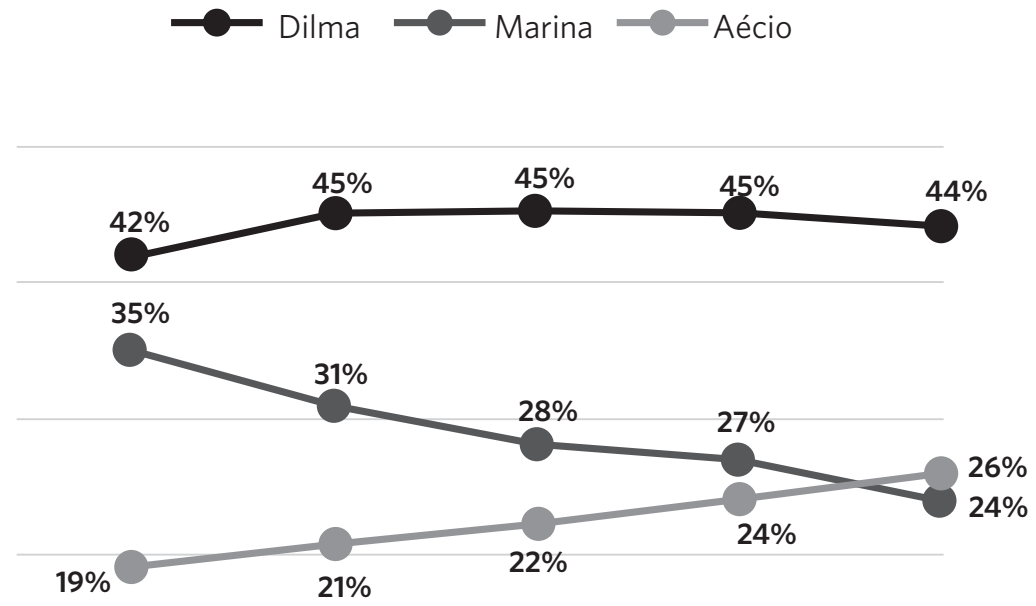

19 Set

26 Set

30 Set

02 Out

04 Out

Fonte: Reis 5

A queda de intenção de votos em Marina Silva foi produto de uma intensa campanha de desconstrução de sua imagem, fenômeno que se repetiria no segundo turno em relação à candidatura de Aécio Neves, desta feita acusado de agressor de mulheres. A intenção da campanha adversária era a de comover o eleitorado feminino que, naquele momento, era responsável pelo maior contingente de indecisos. Uma pesquisa interna realizada pela campanha de Dilma Rousseff teria revelado que parte significativa desse contingente feminino de indecisos teria casos de violência intrafamiliar na infância ou na vida adulta.

A campanha agressiva passou a atingir o perfil e biografia dos adversários, em uma nítida tentativa de reduzir a empatia do eleitorado não cativo. A agressividade empregada gerou uma reação em escala dos adversários, que passaram a assumir, durante e após o processo eleitoral, revolta e indignação. Esse foi o movimento que promoveu a aproximação de algumas lideranças de oposição ao lulismo (em especial, do Partido da Social Democracia Brasileira e de outras agremiações aliadas) às organizações juvenis de extrema-direita que começavam a se estruturar. Ao final do segundo turno, já se contabilizavam quinze mil jovens arregimentados em comunidades formadas nas redes sociais que apoiavam abertamente a candidatura de Aécio Neves e se opunham ferrenhamente ao governo Dilma Rousseff e ao lulismo. Começava a organização, de fato, 
de uma parcela da juventude que se afirmava como de direita ${ }^{28,29}$.

Em 2014, foi fundado o Movimento Brasil Livre (MBL), que protagonizaria, nos anos seguintes, uma ofensiva de direita tendo como primeiro objetivo a deposição do governo Dilma Rousseff. Matérias divulgadas na grande imprensa nacional indicaram o financiamento dessa organização de direita por partidos políticos. O portal UOL foi um dos veículos que divulgaram esses vínculos. Em matéria intitulada 'Áudios mostram que partidos financiaram MBL em atos pró-impeachment', publicada em 27 de maio de 2016, o portal de notícias informava que ${ }^{30}$ :

O MBL (Movimento Brasil Livre), entidade civil criada em 2014 para combater a corrupção e lutar pelo impeachment da presidente Dilma Rousseff (PT), recebeu apoio financeiro, como impressão de panfletos e uso de carros de som, de partidos políticos como o PMDB e o Solidariedade. Quando fundado, o movimento se definia como apartidário e sem ligações financeiras com siglas políticas.

Repercutindo esta matéria, a revista 'Exame'31 sustentou o envolvimento do Partido da Social Democracia Brasileira (PSDB), Democratas (DEM) e Partido do Movimento Democrático Brasileiro (PMDB):

Em áudios, um dos coordenadores do MBL, Renan Antônio Ferreira dos Santos, e o secretário da Mobilização da Juventude do PSDB do Rio de Janeiro, Ygor Oliveira, confirmam a ajuda do PSDB, DEM e PMDB para realizar os protestos do dia 13 de março deste ano.

Pesquisa realizada por Kátia Gerab Baggio demonstrou vínculos de várias organizações estudantis e juvenis (entre elas, o MBL) com redes de organizações de direita lideradas pela Atlas Network ${ }^{32}$. Esta organização, que possui 484 parceiros em 92 países, é uma think tank norte-americana, cuja sede está situada em Washington, D.C. Fundada em 1981, ela propaga concepções de direita e propostas programáticas ultraliberais, bem como recebe recursos de fundações, corporações e doações individuais. Entre seus patrocinadores, estão os irmãos Koch, empresários do setor de petróleo e gás. No Brasil, ela mantém 12 parcerias, algumas vinculadas à organização estudantil Estudiantes por la Libertad, ramificação da Studentes For Liberty, que, no País, possui como afiliadas a Estudantes Pela Liberdade (em Belo Horizonte) e Students For Liberty Brasil (em São Paulo) ${ }^{32}$.

O MBL se vinculou direta e indiretamente a essas organizações por intermédio da Red Liberal de América Latina (Relial), criada em 2004. Seu vice-presidente é Ricardo Gomes, também membro do Conselho Deliberativo do Instituto de Estudos Empresariais do Rio de Janeiro. A autora revela que o MBL e o Instituto Millenium apareciam em uma listagem de parceiros dessas organizações, listagem de $2016^{33}$.

Não há, portanto, nenhum registro de estrutura organizativa articulada nacionalmente antes de 2014. Muito menos coletivos ou organizações de extrema-direita com fluxo de financiamento de partidos políticos ou redes internacionais como as identificadas com forte atuação a partir de 2014 e 2015.

Teríamos, na verdade, um desencontro de narrativas sobre um processo político-social que colocou em xeque as estruturas de representação hegemônicas do século XX: estruturas verticais, de organização duradoura, com forte coesão interna e focadas em programas ou direitos objetivados em pautas definidas entre seus membros. É deste desencontro que se trata o período que vai de 2013 a 2017.

\section{O desencontro de narrativas e formas de organização social}

A tese central que estou propondo neste texto é que 2013 promoveu uma ruptura com modelos organizativos tipicamente modernos e que foram hegemônicos em nosso país ao 
longo do século XX. Estruturas 'totais e totalizantes', que abarcavam seus afiliados em um feixe estruturado em representações delegadas, em estruturas administrativas internas e em processos decisórios definidos em regras relativamente perenes que garantiam uma forte unidade e identidade coletiva.

Em 2013, essa lógica organizativa foi contestada por manifestações de massa que sugeriram, em três semanas, uma 'manifestação mosaico', estilhaçada em múltiplas demandas e estruturas minimalistas autodenominadas de coletivos. Os processos decisórios foram todos assembleísticos, fundados em mecanismos de democracia direta, em que o respeito à individualidade e às minorias foi a tônica do início ao fim.

A resposta do governo federal às mobilizações de 2013 foi errática. Começou apresentando uma proposta de atendimento do que considerava o fulcro das demandas apresentadas nas ruas para, logo em seguida, passar a perseguir e a desmontar a fluida e ainda tênue novidade organizativa que havia surgido no final do primeiro semestre. A perseguição prosseguiu ao longo do segundo semestre de 2013 e foi ainda mais intensa no primeiro semestre de 2014, quando o Brasil sediou a Copa do Mundo de Futebol.

Contudo, as manifestações haviam criado várias fissuras, tanto na popularidade do governo federal, herdeiro formal dos populares governos Lula, quanto no método de organização social que emergiu nos anos 1980, durante o processo de redemocratização do País, e que deitou raízes na política nacional nos anos seguintes.

Foi, portanto, uma ruptura de narrativas políticas e sociais. Este parece ter sido o pano de fundo desse intenso período político.

Essa hipótese explicativa auxilia na compreensão dos motivos para emergir uma forte mobilização de extrema-direita em nosso país que consegue liderar ações públicas pelo impeachment de Dilma Rousseff, mas que, já no final de 2016 e durante 2017, já revelava dificuldades para criar fatos políticos e mobilizações de rua. Ao contrário, entre 2016 e 2017, várias ações das organizações clássicas de esquerda (partidos, sindicatos e alguns movimentos sociais) lideraram atos e manifestações gigantes que culminaram com a greve geral de 28 de abril de 2017, considerada a maior greve dessa natureza realizada em nosso país. A despeito desse feito, a partir do segundo semestre daquele ano, a mobilização de esquerda perdeu força, assim como as mobilizações de extrema-direita que reivindicavam a intervenção militar.

O Brasil retornou à prostração social do período anterior a 2013. Agora, contudo, com as estruturas de representação esfaceladas e em profunda crise.

Mergulhados na maior rejeição popular da história recente do Brasil, o Congresso Nacional e o governo federal impuseram, até meados de 2017, reformas que desestabilizaram ainda mais várias das organizações sociais oriundas do período de redemocratização do País. Este foi o caso da reforma trabalhista que, após sua aprovação, mergulhou as estruturas sindicais em uma crise de financiamento, com as centrais sindicais perdendo mais de $80 \%$ de sua receita no final do primeiro semestre de 2018. A partir de então, o governo federal não conseguiu liderar forças políticas para emplacar mais reformas, tendo a reforma da previdência social como sua maior ambição.

Como se percebe, houve um confronto de modelos de representação e organização (e até mesmo de ocupação dos espaços públicos e validade do campo institucional) que se chocaram em 2013 e em 2014 e que acabou por abrir uma brecha - pela crise de representação que se instalou - às forças de direita e extrema-direita. Brecha aberta pelo desencanto com os modelos políticos vigentes que afetou, em um primeiro momento, $o$ governo Dilma Rousseff, mas que continuou disseminando o sentimento antissistêmico que se instalou em nossa sociedade. A política de ciclo curto se instalou, como um processo permanente de deslegitimação de 
todas forças políticas estabelecidas, tanto as que se instalaram após o governo Dilma quanto as que procuraram desautorizar o governo Temer, à direita ou à esquerda.

Um segundo aspecto a destacar é a mudança de padrão de protesto social no Brasil. Do modelo de organização definido em 1980 para o modelo fragmentado de 2013. Do mobilismo que assegurava força às lideranças sociais que passavam a negociar com as estruturas de poder vigentes para a provisoriedade à horizontalidade e à cultura anti-institucionalista. Do padrão de movimentos sociais, mais perenes e estruturados, para o de mobilizações sociais, mais fluidas e instáveis.

Os dois padrões parecem inscritos na vida política nacional, mas sem capacidade de criar soluções políticas consistentes. Uma, por parecer representar uma parte da sociedade e encontrar-se, em certa medida, em crise (em especial, no mundo sindical); outra, por se recusar a dialogar com o campo institucional.

A extrema-direita se insurgiu justamente nessa lacuna representativa que indicou que o pacto redemocratizante dos anos 1980 dava sinais de esgotamento. Se 2013 teve alguma participação no fim da hibernação pública das forças brasileiras de extrema-direita, esta foi a de revelar esse esgotamento. Todavia, mesmo a retomada do discurso e de práticas de extrema-direita - o uso constante da violência como recurso de intimidação e perseguição política - parece ter sido tópica (2015 e 2016, em especial), inserida na crise de representação que toma todo o País.

Nada mais significativo que o dado revelado pelo Latinobarômetro de 2018: somente $7 \%$ dos brasileiros confiam nos seus conterrâneos, o menor índice de confiança interpessoal da América Latina ${ }^{32}$. O índice de satisfação dos brasileiros com o regime democrático também ficou abaixo da média da região (que é de $30 \%$, tendo Uruguai, com $57 \%$; Nicarágua, com $52 \%$; e Equador, com $51 \%$, à frente).

Vivemos, enfim, um desencontro entre representantes e representados, entre as formas clássicas de representação e as novas e polissêmicas formas de organização social. Desse desencontro, nascem as narrativas das intensas mobilizações sociais inauguradas em 2013. Narrativas que procuram interpretar um divórcio ainda não solucionado e, em muitos casos, fundadas em desejos de retorno de uma época em que o mundo político parecia mais estável. A política de ciclo curto parece ter se instalado no Brasil. E não sabemos quando poderá ser superada. 


\section{Referências}

1. Doimo AM. A vez e a voz do popular: movimentos sociais e participação política no Brasil pós-70. Rio de Janeiro: Relume-Dumará; 1995.

2. Giovanni G, Nogueira MA, organizadores. Dicionário de Políticas Públicas. São Paulo: Imprensa oficial do Estado de São Paulo; 2013.

3. Melucci A. Acción colectiva, vida cotidiana y democracia. México: El Colégio de México; Centro de Estúdios Sociológicos; 1999.

4. Malini F, Antoun H. A internet e a rua: Ciberativismo e Mobilização nas redes sociais. Porto Alegre: Sulina; 2013.

5. Reis T. Veja a intenção de voto para presidente em SP, RJ, MG e DF, segundo o ibope. G1 [internet]. 2014 set 30 [acesso em 2018 jul 1]. Disponível em: http://gl.globo.com/politica/eleicoes/2014/blog/ eleicao-em-numeros/post/veja-intencao-de-voto-para-presidente-em-sp-rj-mg-e-df-segundo-o-ibope.html.

6. Sodré M. Liberdade de viver no espelho. Estado de S. Paulo [internet]. 2014 dez 20 [acesso em 2018 jul 1]. Disponível em https://alias.estadao.com.br/noticias/geral,liberdade-de-viver-no-espelho,1610001.

7. Burt RS. Structural Holes: The Social Structure of Competition. Cambridge: Harvard University; 1995.

8. Hardt M, Negri A. Multidão: guerra e democracia na era do Império. Rio de Janeiro: Record; 2005.

9. Negri A. A Constituição do Comum [palestra transcrita]. In: II Seminário Internacional Capitalismo Cognitivo - Economia do Conhecimento e a Constituição do Comum; 2005 out 24-25. Rio de Janeiro: RITS; 2005 [acesso em 2018 jul 1]. Disponível em http://fabiomalini.com/dossie-negri-e-foucault/a-constituicao-do-comum-por-antonio-negri/.

10. Fachin P. Movimentos tradicionais, autonomistas e um novo ciclo de lutas no Brasil: entrevista especial com Alana Moraes. São Leopoldo: IHU-Unisinos; 2017 [acesso em 2018 jul 1]. Disponível em: http://www.ihu.unisinos.br/159-noticias/ entrevistas/567067-movimentos-tradicionais-autonomistas-e-um-novo-ciclo-de-lutas-no-brasil-entrevista-especial-com-alana-moraes.

11. Liclider JCR, Taylor RW. The computer as a communication device. Science Technol. 1968 abr; 76.

12. Sennett R. O declínio do homem público. São Paulo: Cia das Letras; 1989.

13. Dupuy JP. Aux origines des sciences cognitives. Paris: La Découverte; 1994.

14. Loveluck B. Redes, Liberdades e Controle. Petrópolis: Vozes; 2018.

15. Carazai EH, Pitombo JP. Promessas pós-protestos ficam na gaveta [internet]. Folha de S. Paulo. 2014 jun 7 [acesso em 2018 jul 1]. Disponível em https://m. folha.uol.com.br/poder/2014/06/1466713-promessas-pos-protestos-ficam-na-gaveta.shtml.

16. Ricci R, Arley P. Nas Ruas: a outra política que emergiu em junho de 2013. Belo Horizonte: Letramento; 2014.

17. Fausto B. A revolução de 1930: história e historiografia. São Paulo: Cia das Letras; 1997.

18. Decca E. 1930: o silêncio dos vencidos. São Paulo: Brasiliense; 1981.

19. Dupuis-Déri F. Black Blocs. São Paulo: Veneta; 2014.

20. Mendes P. Cardozo diz que reunirá secretários contra atos de vândalos em SP e RJ. G1 [internet]. 2013 out 29 [acesso em 2018 jul 6]. Disponível em: http:// gl.globo.com/politica/noticia/2013/10/cardozo-diz-que-reunira-secretarios-contra-atos-de-vandalos-em-sp-e-rj.html.

21. Galhardo R. Planalto e PT agem para evitar onda 
de violência na Copa e dano eleitoral. O Estado de S. Paulo [internet]. 2014 jan 22 [acesso em 2018 jul 6]. Disponível em: https://politica.estadao.com. br/noticias/eleicoes, planalto-e-pt-agem-para-evitar-onda-de-violencia-na-copa-e-dano-eleitoral-imp-,1121281.

22. Mello PC. Paramilitares americanos treinam policiais brasileiros para a Copa. Folha de S. Paulo [internet]. 2014 abr 21 [acesso em 2018 jul 6]. Disponível em: https:/wwwl.folha.uol.com.br/ cotidiano/2014/04/1443261-paramilitares-americanos-treinam-policiais-brasileiros-para-a-copa. shtml.

23. Ministério da Defesa. Estado-Maior Conjunto das Forças Armadas. Garantia da Lei e da Ordem [internet]. Brasília, DF: Ministério da Defesa; 2013 [acesso em 2018 jul 6]. Disponível em: https://www. defesa.gov.br/arquivos/File/doutrinamilitar/listadepublicacoesEMD/md33_m_10_glo_1_ed2013.pdf.

24. Entenda o que são os rolezinhos e a repercussão que causaram na internet. Diário Catarinense [internet]. 2014 jan 15 [acesso em 2018 jul 6]. Disponível em: http://dc.clicrbs.com.br/sc/noticias/noticia/2014/01/entenda-o-que-sao-os-rolezinhos-e-a-repercussao-que-causaram-na-internet-4390554.html.

25. Professora é afastada da PUC-Rio por ironizar passageiro. Agência Estado [internet]. 2014 fev 17 [acesso em 2018 jul 6]. Disponível em: https://www. estadao.com.br/noticias/geral,professora-e-afastada-da-puc-rio-por-ironizar-passageiro,1131398.

26. Suarez J. Caldeirão de Hamburgo é tática criada por alemães em 1986. O Tempo Brasil [internet]. 2014 jun 17 [acesso em 2018 jul 6]. Disponível em: https://www.otempo.com.br/capa/ brasil/caldeir\%C3\%A3o-de-hamburgo-\%C3\%A9-t $\%$ C $3 \%$ Altica-criada-por-alem \% C3\%A3es-em-1986-1.866251.

27. Ativista é presa em Belo Horizonte. Fórum [inter- net]. 2014 jun 13 [acesso em 2018 jul 6]. Disponível em: https://www.revistaforum.com.br/ativista-e-presa-em-belo-horizonte/.

28. Maisonnave F. Dilma mudou paradigma de campanha eleitoral no país, diz Rudá Rucci. Folha de S. Paulo [internet]. 2014 nov 8 [acesso em 2018 jul 6]. Disponível em: https://wwwl.folha.uol.com.br/ poder/2014/11/1545232-dilma-mudou-paradigma-de-campanha-eleitoral-no-pais-diz-ruda-rucci. shtml.

29. Ricci R. Memórias de 2014: a eleição que não queria acabar. Belo Horizonte: Letramento; 2015.

30. Lopes P, Segalla V. Áudios mostram que partidos financiaram MBL em atos pró-impeachment. UOL Notícias [internet]. 2016 maio 27 [acesso em 2018 jul 6]. Disponível em: https://noticias.uol.com.br/ politica/ultimas-noticias/2016/05/27/maquina-de-partidos-foi-utilizada-em-atos-pro-impeachment-diz-lider-do-mbl.htm.

31. Granato L. Partidos financiaram movimento contra Dilma, diz site. Exame [internet]. 2016 maio 27 [acesso em 2018 jul 6]. Disponível em: https://exame.abril.com.br/brasil/mbl-teve-financiamento-de-partidos-em-atos-mostram-audios/.

32. Baggio KG. Conexões ultraliberais nas Américas: o think tank norte-americano Atlas Network e suas vinculações com organizações latino-americanas. In: Souza RSR. Democracia em Crise: o Brasil contemporâneo. Belo Horizonte: PUC Minas; 2017. p. 115-148.

33. Latinobarómetro: Opinión Pública Latinoamericana [internet]. Santiago: Latinobarómetro; 2018 [acesso em 2018 jul 7]. Disponível em: http://www. latinobarometro.org/lat.jsp.

Recebido em 12/07/2018

Aprovado em 19/09/2018

Conflito de interesses: inexistente

Suporte financeiro: não houve 